\title{
Téoros
}

Revue de recherche en tourisme

\section{The Tourist Destination Periphery in a Comparative Context: in Quebec and Northern Scandinavia}

\author{
Jan O. Lundgren
}

Volume 13, numéro 1, mars 1994

Bas-Saint-Laurent, Gaspésie, Iles-de-la-Madeleine : fascinantes

périphéries

URI : https://id.erudit.org/iderudit/1077773ar

DOI : https://doi.org/10.7202/1077773ar

Aller au sommaire du numéro

Éditeur(s)

Université du Québec à Montréal

ISSN

0712-8657 (imprimé)

1923-2705 (numérique)

Découvrir la revue

Citer cet article

Lundgren, J. O. (1994). The Tourist Destination Periphery in a Comparative

Context: in Quebec and Northern Scandinavia. Téoros, 13(1), 29-33.

https://doi.org/10.7202/1077773ar 


\section{The Tourist Destination Periphery in a Comparative Context : in Quebec and Northern Scandinavia \\ Jan O. Lundgren"}

\section{Introduction}

The touristphenomenon can be viewed from a variety of perspectives and for very different purposes. Since social scientists started to study leisure, recreation and tourism in earnest in the 1950 s the field has become quite filled. Being a geographer, I became interested in the tourism phenomenon some 25 years ago upon my arrival to Montreal, Quebec and Canada from Sweden. The fact that I was migrating from one boreal environment to a similar one on this side of the Atlantic must have been an influence. Also, the fact that recreation and tourism - historically - had been a major factor in the landscape transformation in a region close to Montreal - the Laurentians - was living proof of the force of tourism upon the landscape - its geography, its resources, and its economy. Thus, the Laurentians one of the older tourist regions in Canada - came to serve as a conveniently located laboratory for theobservation of recreation and tourism on a regional level and in a particular landscape context.

\section{The purpose of this analysis}

This Teoros colloquium on tourism has as its general theme the study of tourism in goographically peripheral destination conditions. The reason for this orientation is quite obvious - tourism in Canada and in Quebec usually involves travel movements centrifugal in character, starting from centrally located travel-generating areas and moving out toward the periphery, i.e. less populated, often uninhabited destination zones often also located toward the North. Thus, one gets the general impression, actually an erroneous one, that the built-in centrifugal power of tourist travel flows on the whole, is oriented toward remote and underpopulated regions, and consequently play a lesser on role in centrally located destination environments, such as Hull, Montreal, Trois Rivieres,

Mr. Jan O. Lundgren is professor of gecgraphy at MoGill University.
Quebec City - the economic-industrial center spine in Quebec's economy. This is of course not the case at all: the economic dimensions of the tourism phenomenon and tourist industry in many of the major urban centers are probably larger than those of more peripheral destination regions. However, in relative terms tourism matters more to the regional economies in peripheral destination, be they in the Eastern Townships, the Laurentians or along the two shorelines of the Gulf of St. Lawrence, including the Gaspesic, the venue for this colloquium.

The objective of this paper is to present a regional comparison of peripheral tourist destinations, the assumption being that we can benefit from experiences of touristbased development processes that have operated - and still operate - under comparable tourist - geographic settings and in locations, where in many respects factors that impinge upon the destination region are similar, but where, nonetheless, the regional results have turned out differently. The methodology for this comparison is simple: first, a set of principal variables will be defined and their role relative to the development process will be elaborated; the second part of the analysis involves a short comparative overview of the characteristics of the developmentprocess as such in N. Sweden; a third part is more of a conclusion statement, in which wlessonsw will be identified and their possible application to regional peripheries in Quebec will be evaluated. It is assumed that the principal features of Quebec's peripheral tourist development processes are well known to the reader.

The Scandinavian periphery used in this comparison includes *the Swedish Border Mountain Zone (SBMZ) - an area, which has its most southern part approximately $400 \mathrm{~km}$ northwest of Stockholm. From there it stretches north for a distance of over $800 \mathrm{~km}$ hugging the Norwegian border, with an average depth of some $200 \mathrm{~km}$. North of the Arctic Circle the area widens into a broader, rectangular space that extends all the way to North Cape in Norway.
Most of the zone resembles the Quebec wildernesszonenorthwest of the Ecumene settlement zone - the Canadian shield including the Laurentians. In geographic terms the SBMZ compares with the distance of Montreal - Gaspe, or Montreal LG2, or Quebec City - Sept-Iles. However, and here the notion of periphicity enters the picture, most of the zone is accessible from a baseline of urban centers located along the Bothnian Gulf, from Gavle in the south to Lulea in the north at an average distance of $250 \mathrm{~km}$ - in some instances even less - indeed a manageable «approach journeyw by car over a high quality road system. Further, the combined population base for the larger counties along the Bothnian Gulf shoreline amounts to approximate 800000 inhabitants, which translates into a substantial tourist travel market. Toward the north, themountain zone widens into the broader Nordkalotten region - an extensive territory of some 650 by $500 \mathrm{~km}$, that in tourist promotional literature usually is treated as a separate area.

\section{The tourist periphery concept}

The notion of a tourist periphery is a central concept, not simply to this colloquium but in the tourist literature in general. A few introductory comments on the concept and the way in which it has developed may be useful before starting our comparison.

The notion of periphicity is not applicable exclusively to the domain of tourism studies or tourist geography. The concept can be related to other social science related fields as well, but is then often hidden under other terms; in economics, for instance, one refers to marginality or diminishing returns; in behavioral geography - a field that touches upon aspects of consumer behavior and travel movements - one talks about «distance decay - the power of distance over consumer travel movements; in agricultural economics, reference is often made to *marginal lands $s$ - to mention some broader applications. 
In tourism geography the periphery concept was introduced in the mid 1950 's by W. Christaller (1954 and 1964) who established the principal outbound *centrifugals characteristic of European vacation travel. The same findings occurred in F. Cribier's La grande migration d'été des citadins en France (1969), which stressed the hierarchal, «pluricentral» system of travel-generating urban centres and the emergence of distinct destination peripheries as a function of urban rank size. The periphery concept thus established becomes a function of travel behavior on regional or national scales. The ultimate elevation of the same behavior to the global level was done in L. Turner/J. Ash's The Golden Hordes (1975) that refers to the *tourist belt which surrounds the great industrialized zones of the worldw (p. 11), a phenomenon that today for the first time is *starting to merge into one giant, global Pleasure Periphery, where the rich of the world relax and intermingles.

Tourist Peripheries are not homogeneous phenomena, a fact that is easily observable both in theory and practice, as F. Rajotte and Miossec stress in their application of the centrifugal character of the tourist travel movement Rajotte develops her differential destination zonation centered on Quebec City (1973) which actually specifies the «wildernesss recreation zone ( $=$ tourist zone); Miossec points to different kinds of destination zones surrounding a generating core, where also the peripbery can generate tourist travellers and in the process create its own destination periphery!

\section{Some factors at play - Case Northern Scandinavia}

For the tourism phenomenon to function in a spatial and geographic context, three functions must interact, sometimes at a high degree of coordination/integration over the tourist's travel itinerary. Pearce has identified them as basic to the tourism system - 1) the travel-generator, where the travel demand is produced; 2) the transport carrier (in the form of private/individual or bulk transport modes - the car, the train/ bus, the passenger aircraft); and 3) the tourist destination which varies depending upon individual travel preferences. In analyzing and comparing the Scandinavian situation with that of the Quebec tourist periphery, the above functions can serve as a useful structure.

First then, The Tourist Resource Base of the Northern Scandinavian tourist region differs from that of Northern Quebec, especially that of the Northshore zone in a number of ways. First, in termsoflandscape and vegetation features both southern and northern sectors of the SBMZ are characterized by distinct sequential elevation zones: as the tourist visitor drives toward the mountain zone, he first traverses an extensive, forested plateau landscape, which in many respects resembles the whole of the Canadian Shield landscape, except the fact that it is less extensive. From a touristical resource perspective this zone has a limited outdoor recreation potential, although sometimes substantial tourist facilitates have emerged. However, other factors than landscape potential often account for their existence: convenient proximity (ex.: Hammarstrand), settlement history and a certain regional/cultural significance (ex.: Jokkmokk), and even urban association (ex.: Gallivare the mining town); the second and thirdlandscape zones takes the traveller straight into *above timberlines topography. The former mostly lacks the jagged alpine character of the Canadian Rockies and rather features a rolling, smooth topography which can ensily be mastered by the hiker - a promenade wilderness if you like. North American comparisons are difficult to find: perhaps the easier parts of the peak zones of the Gaspesie would qualify, or the Mount Kathadin district of Northern Maine. The latter zone has sharper, more jagged features, especially northof the Arcticcircle along the Swedish - Norwegian border where peaks reach over 1500 meters elevation with effective verticals from valley floors often in the range of 500 - 1000 meters. Still, from the point of view of the hiker or climber, even this terrain is mostly manageable without specialized mountaineering equipment in summer; with some care in trail selection the average touring skier can negotiate most of this zone as well. Other physical geographic variables give thezone its tourist appeal: extensive lake systems, which toward the north, borrow their appearance from the Northitalian lakes, buton a slightly large scale add to scenery while with the lakes go parallel river systems that in theory can carry you down to the coast, from where you, the tourist, perhaps came. The seasons are distinct as in the Canadian subarctic regions, with short, six week summers, with long shoulder seasons, a darkwinter thatonly brightens up in March, when the skiers start to come. Summer and winter temperatures are comparable to those around Quebec City and the Lac St. Jean region perhaps with the difference being a harsher winter weather season on this side of the Atlantic.

Secondly, a long settlement bistory adds to the tourist resource base, unless one is searching the pristine environments untouched by man. The SBMZ, as it is the case also for areas outside the zone, have seen both an aboriginal population and, over the past 250 years, colonizers from the South use the lands, especially the valley floors, that often have agricultural potential. Numbers have, however, been quite small. Most of the terrain above the treeline was (and is) used by the migratory Sami and their reindeer flocks. Starting around 1900 , resource industries have been active in the North in general, and have in some cases located well inside the mountain zone : water reservoirs for hydro power development were constructed in the 1960 s and 1970 s and as early as 1900 many rivers saw strings of hydro power plants established. The same era saw mining developments, which rarely entered the mountain zone, but were primarily located on the forest plateau - from Kiruna and Gallivare in the north to Laisvall and Boliden further south. Tourism emerged as a regional factor with the construction of strategic railways, the first phase at the turn of the century. Thus, a discreet network of small villages and periodical market places developed throughout the regions, usually linked into road networks that in turn connected with major regional centers and coastal towns. Consequently, trade and interaction could occur in both directions - inbound and outbound - which made the zone less of a traditional «cul-de-sac destination. And one could always, by crossing one more mountain range and the Norwegian borderdescendinto the magnificent fjordscape on the Atlantic side, which made for an international tourist experience - journeying literally from coast to coast. The climate is typically boreal - the Lac St. Jean-Chibougamau-Manicouagan-SeptIlescorridor comes to mind, with summers that can occasionally be warm, and winters that are cold and crisp.

Thirdly, the access question - the transport function is an essential ingredient to the tourist development process. In Quebec's 
tourist space, communications lines tend to run east-west and only occasionally perpendicular to the Ecumene settlement corridor. There are of course exceptions as of recent decades and also earlier : Le Petit Train du Nord going into the Laurentians, the Chibougamau rail link and more recently (1952) the Sept-Iles-Schefferville line. The strategic access links by rail into the SBMZ were initiatedaround 1900 - the Storlien-Trondheim connection in 1902, the Lulea-Kiruna - Narvik line in 1904. Major road building in the 1970 's produced a number of internordic travel loops catering to the motorist, which in some instances have produced too much traffic intoor through ecologically sensitive areas. Thus, in the postwar period the whole zone has opened up to tourist access on a new level, which also has increased the appeal of visiting.

Fourthly, destination area services represent with the destination as such the important third function that must be in place for the basic tourism system to function. Here restsperhaps a fundamentallydifferentand unique feature in theSBMZ which requires a bit more of an elaborate evaluation than simple calculations of bed capacities and similar standard procedures. Here we have to delve into not only the existence of facilities but also the organizational and development structures that have brought them into place. In peripheral areas this is a critical factor, because a proper backward integration with an effective marketing organization is essential factor for the successful venture on a large scale. The voluntary National Touring Membership Associations enter picture not only in the Swedish North but also in the Finnish and to some degree the Norwegian!

The STF (the Svenska Turistforeningen/ the Swedish Touring Association) and the equivalent FTF (for Finland) is a membershiporganization established in 1885 as a idealistic promoter of tourism as a way of discovering your country: *Know your countrys is the STF motto. From the start the STF was a truly vertically integrated tourist travel organisation, incorporating market-based travel agency retailing, transport services and destination area services in the form of accommodation in both simple and more well equipped facilities. In addition, the STF acted as the recreational organizer by developing the year-round hiking trail system that today spans the whole of the SBMZ, from north

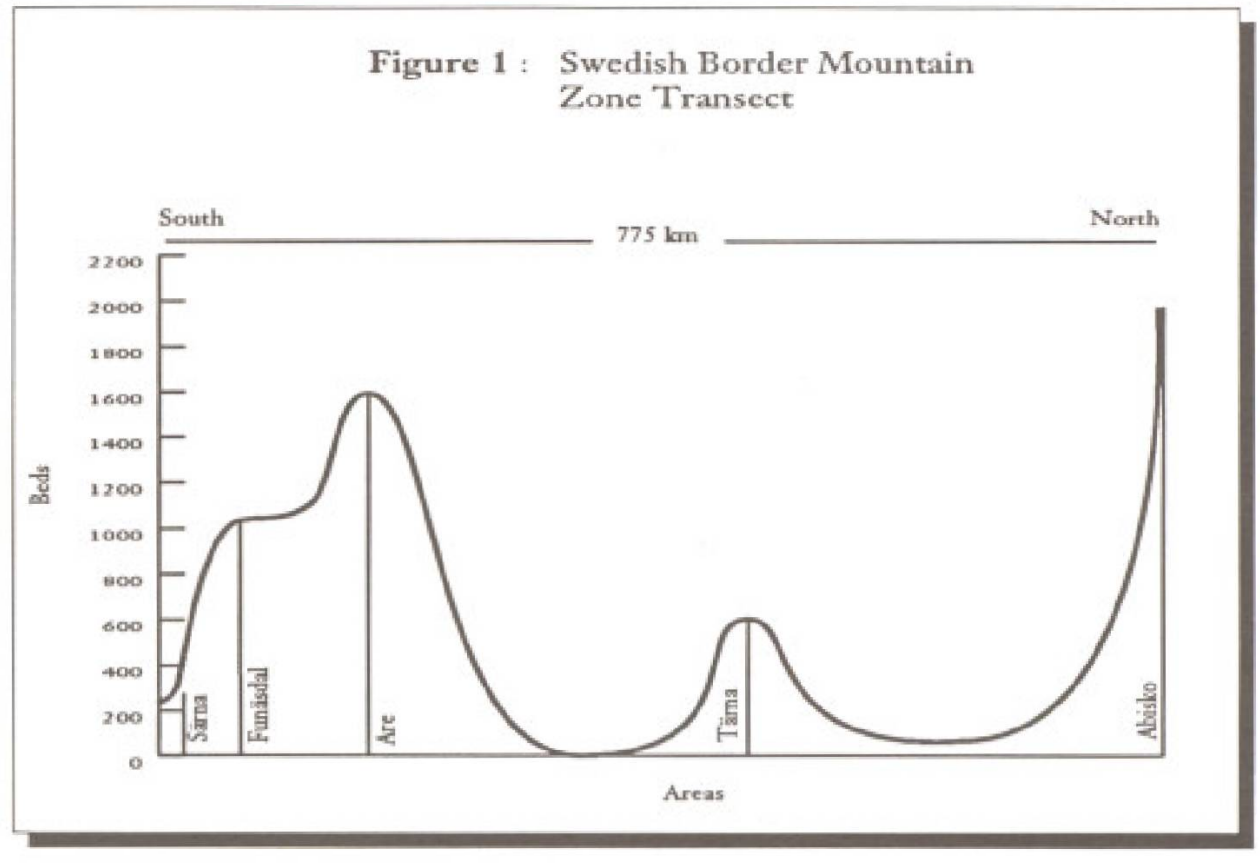

to south, the most well-known part being the King's Trail that connects the Abisko Station with the Hemavan Hostel, a distance of some $300 \mathrm{~km}$ - the bulk above the timberline. The organisation is well represented throughout the lodging industry in the area, with both major resort stations (fully fledged resorts) and with the simpler hosteloperations, thelatter dispersed across the whole country. Of the approximately 10000 beds in the SBMZ region some 10 $\%$ are STF owned, not a dominant factor by any stretch of imagination, nor for that matter the most expensive or luxurious, butnevertheless with a strong market profile aimed at the broad middle-class market segment, and with a strong dose of ecotourism in the promotion. The «stationsw are strung out throughout the mountain zone and vary in size but are above average size. The STF stations and the considerable number of other types of accommodation enterprises - some 70 operations altogether - represent the bulk of service industry investments in the zone, discounting other kinds of facility investments notably ski lifts - and give an idea of the significance of this mountain zone as a tourist destination area. The fact that the operations, with a exception of the Storlien and Are-regions, are fairly evenly dispersed from North to South is an indicator both of the even touristlandscape attractions along the zone and of the generally good access: the baseline cities on the coast play an importantrole here in alleviating the poorer access that exists with the larger metro- politan market further south, notably with the Central Swedish metropolitan market.

The final point that should be made relates to actual landscape usage of the zone for outdoor recreation - an aspect in which the STF traditionally has been heavilyinvolved. The trail system referred to a bove was in its original form developed by the STF and it isonly in recent years that the maintenance of thesystem has been transferred to public regional authorities. In addition to the trail markings for thousands of kilometers of trails developed by the STF, a self-service shelter cabin system along some of the more heavily used links in the system has also been set up, which ensures a certain encountering bad weather conditions or simply in need of more protected overnight facilities.

The development proces assuch for the SBMZ constitutes the final part of our analysis, in which we try to bring together the various functions, especially the accessibility question and the matter of the development of facilities. Although we are discussing the wholeregion there is particular focus upon the northern part, where the SBMZ and the Nordkalotten areas overlap, i.e. in the North, the area that actually saw the initial STF developments already at the turn of the century.

The development of tourist facilities - accommodation, trail systems and also inminimum safety, and comfort, to users 
Figure 2: Development in visitor volume at STF Stations : 1905-1975

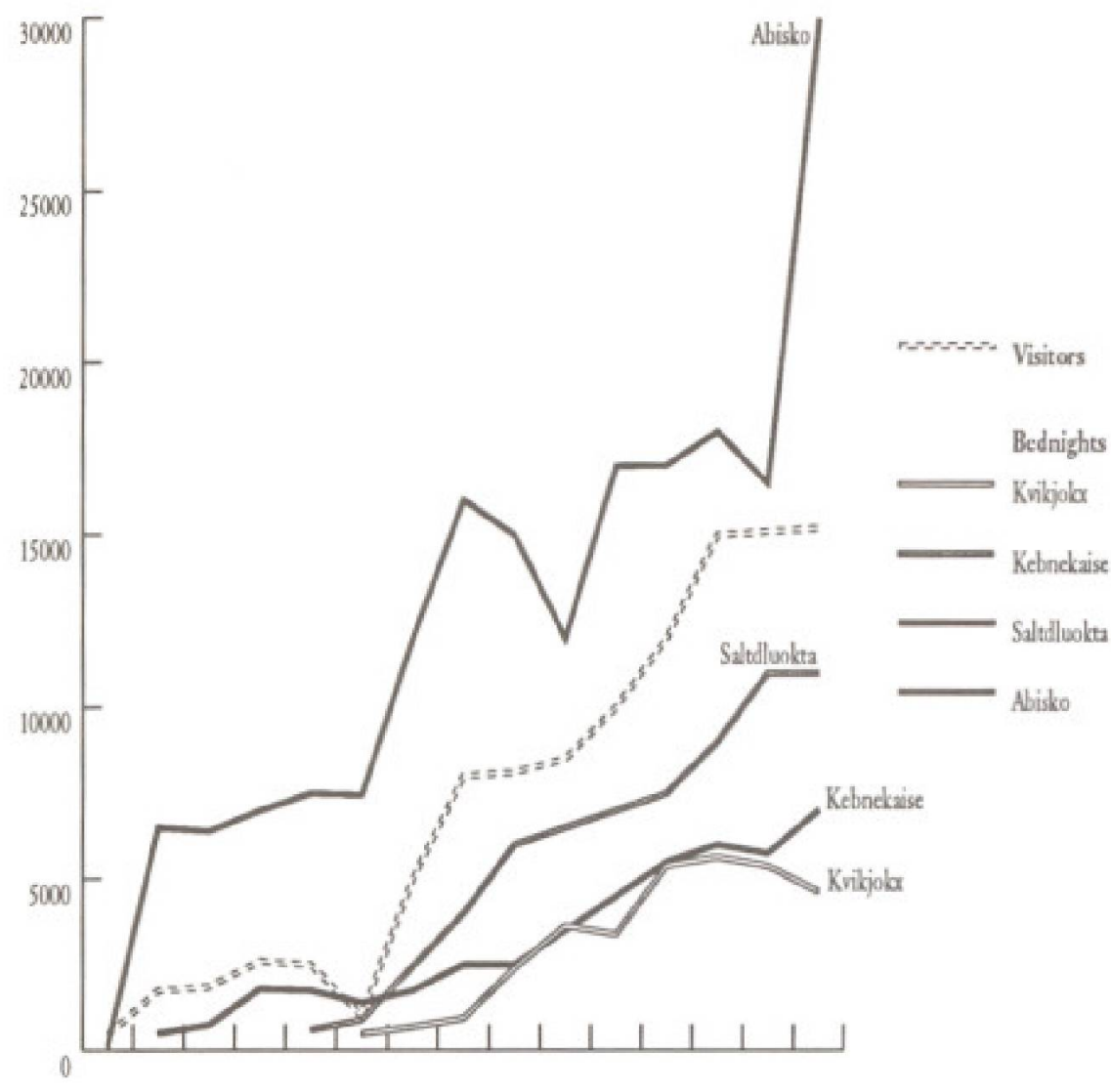

190519101915192019251930193519401945195019851960196519701975 commodation. However, as the STF operated on the retail level providing total inclusive charter arrangements on an individual or a group basis such economical packages were promoted with vigor. As a consequence, the total price could be kept at a very competitive level, in spite of fairly long journeys to destinations. With a few exceptions, through most of the decades leading up to World War II, the type of a tourism that flourished was of rustic type summer hiking from the various mountain stations over the trail system and the same on skis in winter. Numerous methods were used to mobilize new market groups. Thus, in the mid 1920 s, city schools started large scale group travel into the SBMZ, both in its southern part and in the Nordkalotten area. The STF was sometimes involved in this, but it eventually developed into a business entity in its own right.

Needless to say, with transport infrastructure - and services - in place, with active promotion of group arrangements and the activation of the school market the SBMZ emerged as a major tourist destination featuring a wide range of destination area services. The geographic extent - and variation - of the bed capacity can be seen in the South-North geographic transect (fig. 1). Even if the transect simplifies the geographic distribution pattern it nevertheless shows the massive build-up in the southern area - a build-up that has relied upon convenient overnight train access from Stockholm into the Ostersund-AreStorlien corridor. Presently $1 / 3$ of the total SBMZ bed capacity along the tansect is actually found in this area, which testifies to the power and importance of comfortable and - in relative terms - inexpensive approach travel costs to peripheral destination areas. In fact, accessibility is crucial on a broader scale, which can be seen in the heavy concentration of acoommodations to the southernmost $1 / 3$ of the transect's $775 \mathrm{~km}$ that holds almost $70 \%$ of the total accommodation capacity.

The middle zone of the transect is by comparison practically devoid of any major resort developments, which partly can be explained by the more cumbersome transport arrangements required to reach this area, and which therefore can only rely upon tourism generated from the smaller coastal towns, insufficient for truly substantial facility developments. 
Outstanding in the distribution pattern is the Abiskoarea in the far North, not simply by the remarkable capacity of over 2000 beds - ( $21 \%$ of the total $)$ as such but rather by the peripheral location relative to travelgenerating markets. The three major resorts in this remote corner of the SBMZ have bed capacities above 400 on the average, provide practicallyyear round services and cater more than any other operation in the mountain zone to the distant foreign market - the European continent in particular. Still, it is also a popular destination for the coastal city region around Lulea (over 100100 inhabitants) and for the regional population centered on smaller towns closer to the mountain zone - Kiruna and Gallivaare in particular. The development of the Abisko STF Station reads a bit like a developers dream. As Fig. 2 demonstrates, Abisko, combined with some of the other STF operations of more modest size located in the same area northwest of Kiruna, have featured a fairly consistent growth, with only occasional drops in guest volume due to the war years and to the fate of many resort facilities fire. Still, it is clear that the approach of modestmedium-priced, butwell-equipped large-scale facilities, located in such a way that approach travel costs could be successfully reduced through grouparrangements during the early development decades, eventually established the STF mountain station system in the emind of the markets. The scale economy that could be achieved by rail transport concentrated the tourist flow upon a few destinations in this area, which in turn made possible a below-average type of pricing policy, which in turn provided the chance for a continuous momentum in the promotion and development processes. Abisko, through the decades, and the other facility developments in the same area demonstrate that it is indeed possible to provide both comfort and a outdoors tourism experience in the competitive world of tourism - even in remote locations.

\section{And how does this compare with Quebec's tourist periphery?}

The SBMZ has here served as an example of a real world destination area development on a substantial scale in a peripheral destination situation and obviously relates to the theme of this colloquium. What, then can be gleaned from the case pre- sented and what may, to a degree be relevant toperipheral destinationsin Quebec?

To begin with, it must perhaps be stated, that boreal areas in different parts of the world are not necessarily comparable. There are major differences in the Tourist Resource Base composition which must be recognized. Thus, the Quebec periphery is topographically not as imposing as the SBMZ, with admittedlycertain exceptions, such as the Gaspeand the Torngat; further, the seasonal climate variations are sharper in Quebec than even the northernmost part of the SBMZ : the winter lows are deeper, the summer highs are shorter, which affects the economic viability for service industry operations; thirdly, with a few exceptions, the SBMZ has a settlement history that dates backthrough thecenturies and embraces most of the territory with sedentary agriculture and low order urban centers. So, the tourist experience will never be an exclusive wilderness experience.

The transport function has developed differently and works differently. The role of the transport infrastructure stands out. The principal areas of development in the SBMZ were highly dependent upon bulk passenger transport (= train) services, which tended to direct - and concentrate - the tourist inflows to one or two areas. Thus, facility development could almost be guaranteed a substantial flow of tourists, The flow was less dispersed which in turn meant that one could achieve a better economyscale for accommodation services. Third, the role of a vertically integrated business organisation is critical: the STF had a stake botb in resort facilities in the destination and in the retailing of the same resorts through its travel agency system throughout the national market. Thus, it was in the organisation's interest to produce travel arrangements that were competitive.

Further, but harder to prove: the STF could achieve intra-organisational savings to a greater extent than independent commercial operations. The final factor important for the STF - was its membership population, that had a direct interest in the particular kind of tourism promoted by the STF. Membership solidarity was important both in the early years but also later, when additional facilities complemented the old ones. The independent resort operations had a much tougher situation-a situation that resembles the $Q$ uebec situation much more. Here, the resort operations must sell their services on their own - a costly operation, where one can never be sure to hit the market right. In contrast, the STF sales campaign has even today a captive market of some 400000 members to direct the promotion and the marketing toward. No comparable arrangement exists in Quebec and definitely not for peripheral destinations. Ultimately, the Scandinavian market is based on not only a high per capita income, which generates tourist travel as such, but also on a long legal holiday period of a minimum of five weeks. Thus, it is possible for households to organize two or even three special vacation arrangements. As a result, the tourist dollars are more dispersed and can therefore reach into peripheral destinations. In the Quebec economy, in contrast there are built - in constraints that make tourist travel into peripheral destinations less common. If you only have one vacation period, then you play it safe! And under such conditions what is the purpose of going to the remote periphery? Nah, let's go South!!!

\section{BIBLIOGRAPHY}

Note: The references listed below are placed in the order by which they occur in the paper text.

MIOSSEC J.M. Un modele de respace towistique, L'espace gbographique, no 6, 1, 1977, pp. 41-48. CHAISTALLER, W. Some Considerations of Tourism Location in Europe: The Peripheral Regions Underveloped Countries - Recreation, Areas, RSA, papers XII, Lund Congress, 1964.

CRIBIER, F., La grande migration d'été dos citadins en France, Centre national de la recherche scientifique, Paris, 1969, 403 p.

PEARCE, Douglas, Tourist Development, Longmans, London, 1981.

RAJOTTE, F., The Recreational Hinterland of Quebee Chy, unpublished Ph.D. dissertation, Geography Department, McGill University, Montreal, 1973.

LUNDGREN, J.. Tounsm Development in the Northern Periphery. Toor os, vol, 6, no 1. Montreal, 1987 , pp. 13-19.

STF.SVENSKA TURISTFORENINGEN, Annual Direetories of Hotels and Pensions in Swaden, hotel business data extracted from STF Yearbooks for selected years; STF lodging statistics.

TUANEF, L. and J. ASH, The Golden Hor des - The International Plesaure Periphery. Constable, London, $1974,319 \mathrm{p}$.

SOU SWEDISH ROYAL COMMISSION, Turism och Rakraation i Svarige, 1973.

NATIONAL ATLAS OVER SVERIGE (Swedish National Atlas Series), on physical geography and climate information, 1975.

SOMME, A, Geography of Nordan/The Atlas Section, Oslo, Norway, 1960. 